\title{
Development of smart machine for sorting of deceased onions
}

\author{
Kokate Mahadeo Digamber ${ }^{1}$, Wankhede Vishal Ashok ${ }^{2}$, Pawar Dhananjay Jagdish ${ }^{1}$ \\ 'Department of Electronics and Telecommunication Engineering, SNJB's L. S. K. B. J. College of Engineering, Chandwad, India \\ ${ }^{2}$ Department of Electronics and Telecommunication Engineering, SNJB's SHHJB Polytechnic, Chandwad, India
}

\begin{tabular}{l} 
Article Info \\
\hline Article history: \\
Received Mar 11, 2021 \\
Revised Oct 15, 2021 \\
Accepted Nov 30, 2021 \\
\hline
\end{tabular}

Keywords:

Automated system

BLOB analysis

Gas sensing

Image processing

Onion grading

Onion sorting

\section{Corresponding Author:}

Kokate Mahadeo Digamber

Department of Electronics and Telecommunication Engineering,

SNJB's L. S. K. B. J. College of Engineering

Chandwad, India

Email: mdkokate66@gmail.com

\begin{abstract}
Today, we are thinking to raise farmer's income through various means and measures. Implementation of new crop patterns, technology inclusion and promoting the eshtablishment of numerous agro processing industries will play a major role in agriculture sector. The labour issue is also one of the main concerns in many of the agricultural activities. In this paper we propose a technological evolvement in onion detection process, where we apply image processing and sensory mechanism to identify sprouted and rotten onions respectively. This will yield to quick, accurate and prompt supply of goods to the market, irrespective of lack of consistent but costly manpower. The efficiency of this prototype in identifying the sprouted onions with the help of camera is observed to be upto $87 \%$ and also the response of Gas sensing system in detecting rooten onions under prescribed chamber dimensions is analysed and obtained encouraging results.
\end{abstract}

This is an open access article under the CC BY-SA license.

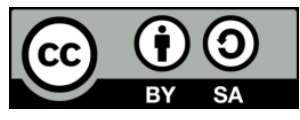

\section{INTRODUCTION}

Agriculture is the back-bone of many of the economies as majority of its population is directly or indirectly engaged in this profession. In recent past, new trends in cropping pattern have been evolved, developed and introduced for changing the economic status of farming community. Onion is important commercial horticultural crop grown in many countries. India is the second largest onion crop producing country in the world. Grading of agricultural produce especially onion has become a prerequisite of trading pan India and even across the borders.

Onion grading is important so as to increase the market value of produce, to meet with global standards and to ultimately fulfill the specific demand of consumer [1]. The majority of onion growers and traders do onion sorting manually; this approach creates issues like subjective grading. This tedious work increases the selling cost, inconsistencies, and results into low productivity.

Most of the above problems can be minimized using automation processes proposed in [2], [3]. The loading of the onion is done through elevator mechanism then by using odor sensor the rotten onion will be removed with the help of pneumatic actuator and blower will blow the mulch then by using conveyor belt and meshing technique onions will be sorted in various grades. Afterwards the automatic weighing of onion bags will be done.

In recent past, the agricultural land and even the farming families have been divided in to micro families with small pieces of land holdings. This has been yielded severely with labor issues and low productivity of agri-based produce. The economy involved in growing the crop is affected largely because of shortage of labors. Design and development of affordable engineering mechanisms to many of agricultural 
process is central theme of this paper. This paper mainly focuses on image processing and gas sensing mechanism used for identification of sprouted and rotten onions. Aim is to design and develop an automatic separator to remove rotten/sprouted onions, for high quality product in market.

\section{LITERATURE REVIEW}

Numerous reseach work has been done on onion grading system and lot of work to be doneon its automation part and performance improvement.

a) Issues and losses incurred in post-harvest processing of onion is reviwed in literature. Maximum aggregate losses have been observed at producer level due to manual, lack of adequate transport utility, drying mechanism, unidenfied rooted bulbs, poor packing facilities, and injury at the time of harvesting [4]-[6].

b) Due to lack of storage facility, the eventual marketing policy of onion is supoosed to be profitable for a middle man and not to a producer [5]. It is a need of the day to apply technology to deploy the proper cold storage facilities with appropriate sorting and sensing units equipped with the system [7].

c) The fragmented supply chain, lack of adequate storage and perishable nature of onion, high marketing margins, and dominance of few traders, are significant challenges in the value chain and need measures to overcome them [8].

d) The majority onion sorting is done manually. Grading of bulbs is carried out on the basis of size and shape for better economic gain [9]. A manually operated sorting machine has been developed in [10]-[12] to achieve minimum injury to onions and reported grading efficiency is of $80 \%$ [10]. But in existing process, farmer's faced certain problems like low productivity, increased labor cost and this process doesn't remove the complete rotten onion in that lot. There is issue of sorting and sorting efficiency in many of the automated systems [13].

e) Supply chain in onion produce and presence of corporate in agrifood processing business will set the new land mark in this area [14], [15].

f) Object or fruit tracking is done by defining the positions of the target in image co-ordinate frames. Image segmentation does selection of certain region and removal of other ground [16], [17]. One of the methods of segmentation is binary large object (BLOB) analysis is frequently discussed in the literature. It is collection of binary information stored as single entity like adiuo or image. With this detection method, points or regions are identified in the given image [18]. BLOB detection method in [19] for survelience system uses foreground mask correction method. Sorting of various fruits using BLOB analysis is studied in [20] and results are obtained using SCILAB.

Most of the above problems faced by farmers and exporters are addressed in this proposed automated process.

\section{RESEARCH METHODOLOGY}

The onion sorting has a potential benefit to farmers, whole sellers and even to retailers. The proper and fast sorting procedure definitely reduces the storage losses. But manual sorting requires huge time and adds labour cost to it. Therefore, there is a need in the onion post-harvest process industry of an efficient and cost-effective sorting system that can identify healthy onion form and diseased one. Design and development of electronic gas sensing nose alongwith image processing tool with actuators which will automatically remove the rotten/sprouted onions is the objective of this paper.

\subsection{Proposed method}

Figure 1 elaborates the system architecture of overall process. Although we have started with above mentioned wider objectives, this article will focus on the electronics engineering part to detect the diseased and damaged onions through scanning and sensing processes. Basically, our system is divided in three units: First is the mechanical part, the loading of onions to the hopper and then passing it on conveyer belt. Second is to pass it through the image processing unit to differentiate the unhealthy onions and finally pass it through the gas chamber for further classification of onions.

In the first part the conveyer belt, pulley and motor mechanism will be designed and assembled, supported by a stiff frame. In the second part, as a first step, we use the camera, based on image processing the onions will be sorted and in the final step they will be passed through the gas chamber. Gas chamber is the complete assembly covered with the Teflon sheet. The circuit designed in the gas chamber is consisting of different gas sensors, temperature and humidity sensor.

Microcontroller [21] is used to control this whole mechanism. When the onion gets damaged or diseased it expels different types of odors. In clean air their conductivity is less whereas when the gas is 
detected the conductivity increases and hence we can detect the diseased onion. When these onions are detected and conductivity is reached at the specified level, the audio-visual alarms will be buzzed and they are separated out using the actuators and hence the healthy onions are separated.

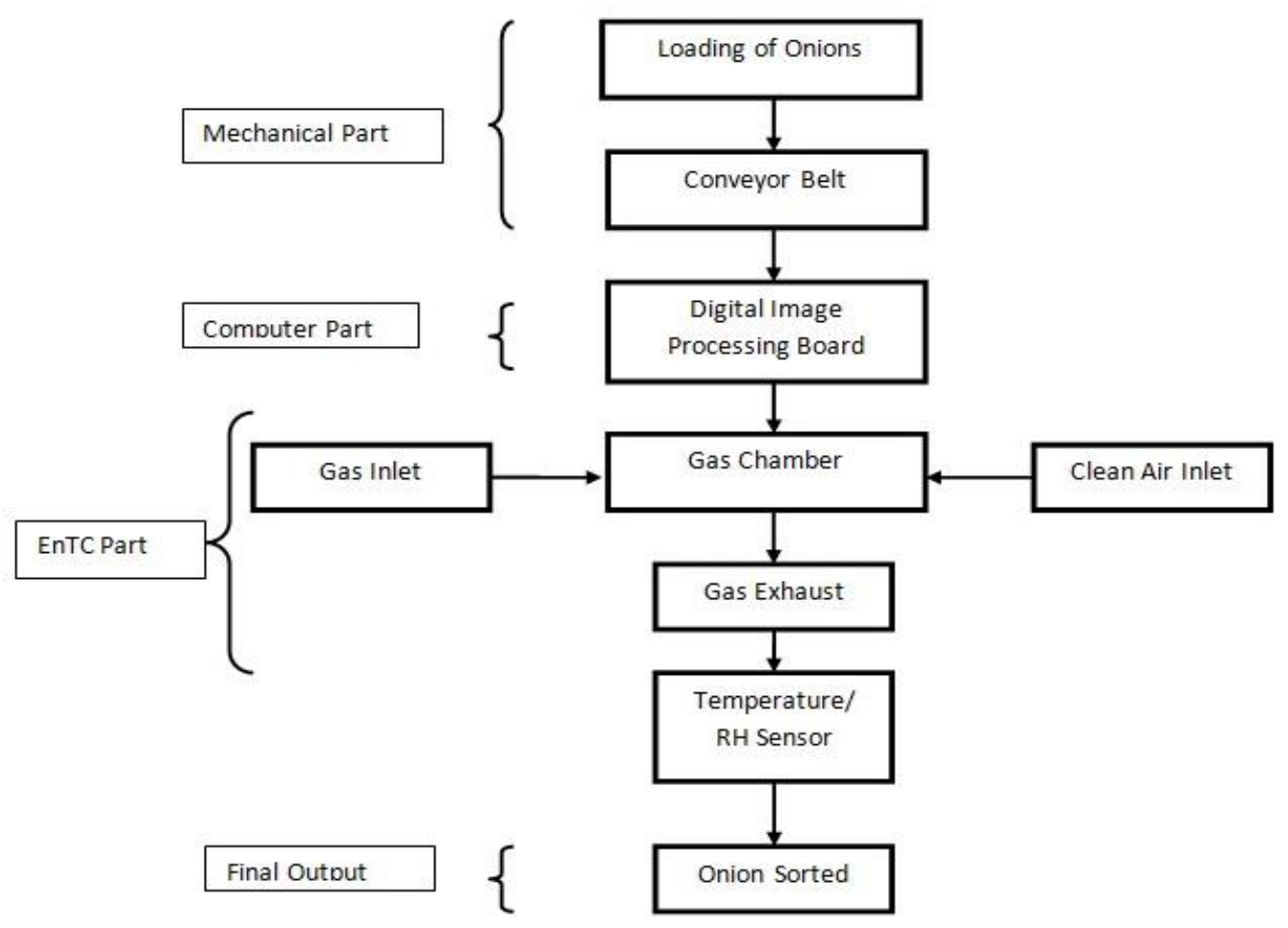

Figure 1. Block diagram

\subsection{Block schematic of system}

The basic block schematic of the system is shown in Figure 1. The system consists various sections based on processes performed or equipment used like loading of onions, conveyer system, various sensors, image processing section, gas chamber and its components. These blocks are connected in sequential manner with reference to process carried out.

\subsection{Detailed descriptions of blocks}

This system is divided in three different units. The first unit is the mechanical frame which consists of the complete frame structure of the conveyer belt, pulley and motor mechanism. The onions are loaded on the conveyer belt and further lined up by passing through the reducer.

Onions are moving towards the chamber in which camera and gas sensors are placed [22]. While onion is passing through chamber, camera clicks the image from video stream and conducts preprocessing of the image received. Preprocessed image is then segmented to separate out the background noise for object evaluation with background removal technique. Thresholding technique has been used to do segmentation. Thereafter, this image is compared with ideal dataset. If image matches with dataset image, then next instruction is given to the actuator. Serious damage like sprouting is easily detected with image processing unit.

Finally, there is a gas chamber followed by image processing unit. As per the investigations in [23], [24], the Gas sensor MQ6 and MQ135 uses $\mathrm{SnO}_{2}$ as sensing layer and able to sense liquefied petroleum gas (LPG), Butane and $\mathrm{H}_{2} \mathrm{~S}$ gases respectively. In this paper these two sensors have been used to detect gases. The gas chamber consists of gas sensors, air controlling valve, and pump to maintain air flow and has two inlets to push clean air into the chamber and one outlet for gas suction of onion and making clean before other onion came into the chamber. Different gas sensors detect the gas sucked from the onions and examines it and sorts out the defected onion. Finally, after processing and examining the onions; the diseased and good onions are separated by the actuators present at the other end of the conveyer belt. 


\subsection{Working of system}

\subsubsection{Digital image processing}

For sorting, to capture onion image, a web camera is used. It comes with high-resolution of 1280x720 pixels to capture an image of H.D. quality. The camera position is adjusted in such a way that it will be convenient for capturing the live image of an onion. The camera is continuously scanning the conveyer belt in video mode. The black background color in image is easier to extract the onion edge characters later. That is why black color is used for the conveyor system. The captured image is given as an input to the software which detects the color of an onion. This data is transferred to system by using USB cable and accordingly control action is taken. The software contains standard reference database of good onions. Then the captured image values are compared with standard reference values. One such example is shown in Figure 2. If the values are not matched then the signal is sent to the actuator to remove that disease onion.

\section{i) Color detection}

In this process, onion color is detected according to red, green, and blue (RGB) values; here onions are sorted according to color. So, for example. two onions are considered say one having redish color and another having sprouts color, so in this step, our work is going to find out color of a onion by using RGB values of a picture taken from the camera.

The following color detection algorithm has been used.

ii) Color detection algorithm:

1) Start

2) Read the input color image using imread function.

3) Read the input pixel of color image in three different planes such as RGB.

4) Convert input image into gray frame.

5) Subtract red color from gray frame using median filter.

6) Convert image into binary and use Blob statistics analysis on this image.

7) Compare the values with threshold value of standard reference values.

8) If input values > threshold values, then onion is bad.

9) Send signal to the arduino.

10) End.

By implementation of above image processing algorithm, results obtained are shown in Figure 2. This simple algorithm is used to detect colors presnt in frame with black background. As shwon in Figure 2(a). It hae only red color components other than black. In Figure 2(b), this frame has red and green color components. Out of which green color components are unwanted. Green color components indicate that sample under test is defective one.

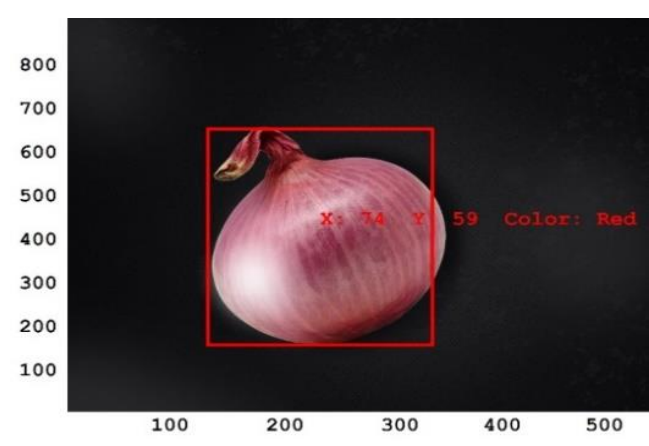

(a)

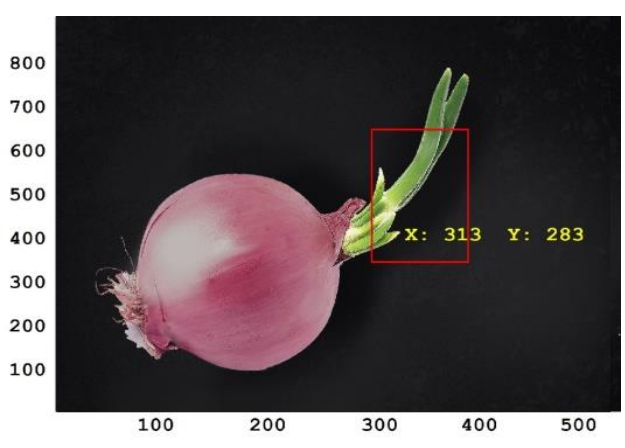

(b)

Figure 2. Testing of samples using image processing; (a) healthy sample and (b) sprouted sample

\subsubsection{Sensing unit}

The MQ6 and MQ135 arrays are utilised to identify the volatile profiles of onions' odour. The controller unit, as well as various peripheral and interface components, make up the electronic device. The following sections describe the device's fabrication, characterisation, and testing. The mechanical components of the Gas chamber were constructed and synced with the conveyor speed to enable the supply 
of odour or fresh air to the chamber housing MQ sensors and efficiently eliminated the chemical odour from the previous experimental set-up [2].

Teflon is used in chamber construction to withstand temperature changes and chemical reactions. The use of Teflon also reduced the risk of contamination from sample odours within the chamber. After customising the middle and lower blocks, a square-shaped Teflon block was cut into three $224310230 \mathrm{~mm}$ portions and stacked on top of each other. To install the MQ series sensors, holes (sockets) were drilled into the bottom block. The size and form of each socket changed depending on the size of the individual MQ sensor [25]-[27]. A circular aperture with a diameter of $112 \mathrm{~mm}$ traversed the central block to provide headspace for the sensors. The samples were pulled into the chamber using a pump and a 3-way valve to choose one of two pneumatic circuits. To dry the chamber, one was given a filter containing charcoal and desiccant (which eliminates humidity and undesirable odours from the air). The gas samples of interest were delivered to the sensor chamber through the other airflow route. The gas was delivered to the chamber through Teflon tubing (outer diameter $=4.76 \mathrm{~mm}$ ). Figure 3 depicts the prototype's actual photograph.
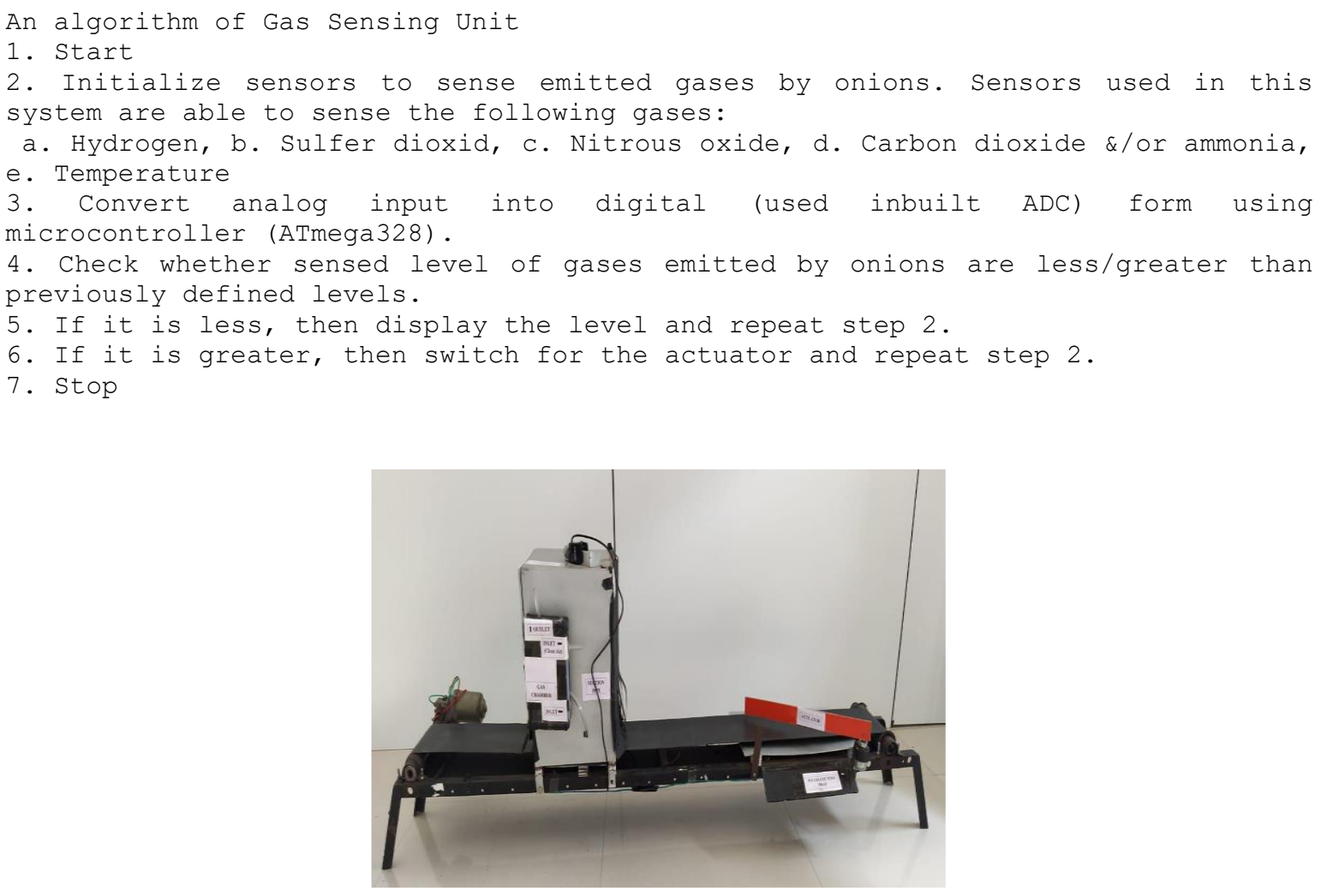

Figure 3. Actual photograph of the prototype

\section{RESULTS AND DISCUSSION}

\subsection{Results of image processing}

\subsubsection{Results of healthy samples}

First objective is to find the color of the onion. There are different methods in image processing to find colors. In this, we used the method of background removal. We blackened the background and then tried to find different colors from it. After Experimenting with this scheme, we found that it seemed to take 3-4 seconds longer than expected time. So the second method we started working on was the bounding box method.

In this we used RGB color module. In the RGB module, we checked the color of the onion and saw the red, green and blue color values of the onion. Then we used a simple method in which we coded a square where only red would appear. Then values of $\mathrm{x}$ and $\mathrm{y}$ coordinates changes due to the arrival of the square. The color of a good onion is only red so from this method we found a good onion [10].

\subsubsection{Results of diseased samples}

But then it was realized that the quantity of good onions was higher than that of rotten onions. If we had been checking the color of good onions, it would have taken us longer time because the quantity of good 
onions would have been higher. Then we decided that if we checked the rotten onions rather than the good ones, they would be separated sooner. The response obtained is as shown in Table 1 and 2 . In rotten onions we saw different varieties like sprouted onions, double onions, and black spotted onions.

Then we tried to find the sprouted onions. But we applied the same logic that was used to find good onions. Just like we checked the red color to find good onions, like wise we checked the green color for the sprouted onions because the onion sprouts are green. When we coded it, we saw that where the green color comes with the onion, the square would come and the values of $\mathrm{X}$ and $\mathrm{Y}$ coordinates would come more than 0 . This means that when the values of $\mathrm{X}$ and $\mathrm{Y}$ coordinates are more than 0 , the onion is sprouted.

Table 1. Responses of healthy samples with image processing tool

\begin{tabular}{lccc}
\hline \multicolumn{1}{c}{ Size } & No of Health samples tested & Accurate Results & Accuracy $(\%)$ \\
\hline Small & 10 & 10 & 100 \\
Medium & 10 & 10 & 100 \\
Large & 10 & 09 & 90 \\
\hline
\end{tabular}

Table 2. Reponses of image processing with diseased samples

\begin{tabular}{lccc}
\hline \multicolumn{1}{c}{ Size } & No of defected Samples Checked & Accurate Results & Accuracy $(\%)$ \\
\hline Small & 15 & 14 & 93 \\
Medium & 15 & 12 & 80 \\
Large & 15 & 12 & 80 \\
\hline
\end{tabular}

As per US Standard 51.4204 [11], the following specific defects shall be considered as serious damage: (a) Sprouting, when the onion has become soft and spongy, (b) Mechanical injury, when more than two of the fleshy scales are badly cracked, cut or bruised. Both of these defects can easily be detected with such an image processing technique.

\subsection{Results of gas sensors}

The Gas collection chamber is designed to test the gases emitted by defected onions. The air sample of Onion is collected in this chamber and output values of various components like, Carbon Dioxide, Carbon Monoxide, Hydrogen are compared with the values of these gases in clean air [5] to check the variation. Above mentioned gas sensors have been used for detection of healthy as well as rotten onions and the prototype has given responses as shown in subsequent tables. When diseased samples are tested using MQ135 sensor for $\mathrm{CO} 2$ and $\mathrm{CO}$ gases, as shown in Table 3, we found that response to $\mathrm{CO} 2$ gas ranges from $7807.13 \mathrm{ppm}$ to $7829.01 \mathrm{ppm}$ while Co gas ranges from $705.17 \mathrm{ppm}$ to $721.01 \mathrm{ppm}$ for 5 random diseased samples. The results shown in Table 4, are obtianed when the healthy samples are tested using MQ135 for $\mathrm{CO}$ and $\mathrm{CO} 2$ gases, we found that response to $\mathrm{CO} 2$ gas ranges from $2480.13 \mathrm{ppm}$ to $2563.34 \mathrm{ppm}$ and Co gas ranges from $343.09 \mathrm{ppm}$ to $359.87 \mathrm{ppm}$. Tables 5 and 6 shows response received from MQ6 sensor for $\mathrm{H}_{2}$ gas for deceased and healthy onions respectively. We found that in deceased case, response to $\mathrm{H}_{2}$ gas ranges from $1699.03 \mathrm{ppm}$ to $17388.50 \mathrm{ppm}$ and for healthy onion response ranges from $122.00 \mathrm{ppm}$ to $192.35 \mathrm{ppm}$.

Table 3. Reponses of MQ135 with diseased samples

\begin{tabular}{ccc}
\hline Sample no. & $\mathrm{CO}_{2}$ & $\mathrm{CO}$ \\
\hline 1 & $7824.43 \mathrm{ppm}$ & $710.06 \mathrm{ppm}$ \\
2 & $7813.09 \mathrm{ppm}$ & $705.17 \mathrm{ppm}$ \\
3 & $7829.01 \mathrm{ppm}$ & $705.39 \mathrm{ppm}$ \\
4 & $7826.43 \mathrm{ppm}$ & $716.19 \mathrm{ppm}$ \\
5 & $7807.13 \mathrm{ppm}$ & $721.01 \mathrm{ppm}$ \\
\hline
\end{tabular}

Table 5. Reponses of MQ6 with diseased samples

\begin{tabular}{cc}
\hline Sample no. & $\mathrm{H}_{2}$ \\
\hline 1 & $1738.50 \mathrm{ppm}$ \\
2 & $1704.61 \mathrm{ppm}$ \\
3 & $1723.07 \mathrm{ppm}$ \\
4 & $1729.43 \mathrm{ppm}$ \\
5 & $1699.03 \mathrm{ppm}$ \\
\hline
\end{tabular}

Table 4. Reponses of MQ135 with healthy samples

\begin{tabular}{ccc}
\hline Sample no. & $\mathrm{CO}_{2}$ & $\mathrm{CO}$ \\
\hline 1 & $2523.07 \mathrm{ppm}$ & $357.00 \mathrm{ppm}$ \\
2 & $2480.13 \mathrm{ppm}$ & $343.09 \mathrm{ppm}$ \\
3 & $2493.93 \mathrm{ppm}$ & $345.07 \mathrm{ppm}$ \\
4 & $2563.34 \mathrm{ppm}$ & $359.87 \mathrm{ppm}$ \\
5 & $2504.02 \mathrm{ppm}$ & $353.10 \mathrm{ppm}$ \\
\hline
\end{tabular}

Table 6. Reponses of MQ6 with healthy samples

\begin{tabular}{cc}
\hline Sample no. & $\mathrm{H}_{2}$ \\
\hline 1 & $192.35 \mathrm{ppm}$ \\
2 & $127.25 \mathrm{ppm}$ \\
3 & $136.08 \mathrm{ppm}$ \\
4 & $122.00 \mathrm{ppm}$ \\
5 & $164.79 \mathrm{ppm}$ \\
\hline
\end{tabular}




\subsubsection{Response of gas sensors}

In practice, threshold setting for sensors is done through various trails. Trails have been conducted to identify the response of sensors in terms of distance and various samples sizes. The distance between samples under test and sensors was kept to 3 and $6 \mathrm{~cm}$ and readings were taken in a place where room temp was noted $31{ }^{\circ} \mathrm{C}$. Figure 4(a) elaborates the response characteristics of MQ135 for $\mathrm{CO}_{2}$ gas at two different distances whereas Figure 4(b) represents response of MQ135 to Co gas. The response of sensor IC MQ6 to $\mathrm{H}_{2}$ is shown in Figure 4(c); here medium size onions are taken into consideration at working temperature of $31{ }^{\circ} \mathrm{C}$. Similarly, Figure 5 shows effect of onion size on performance of MQ135.

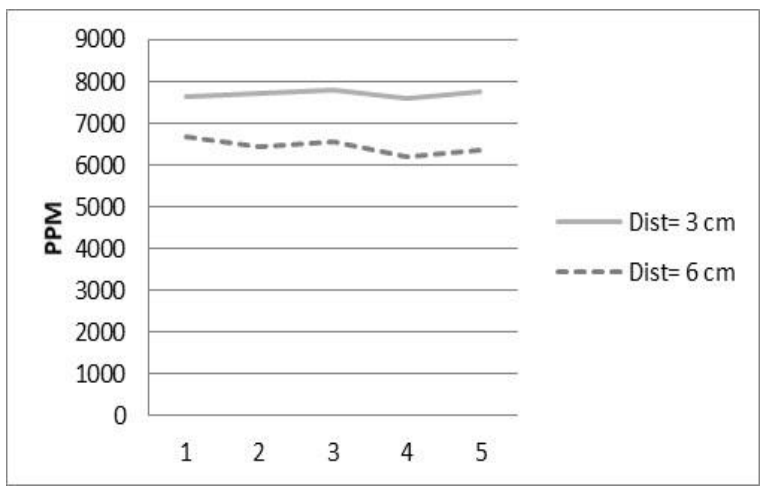

(a)

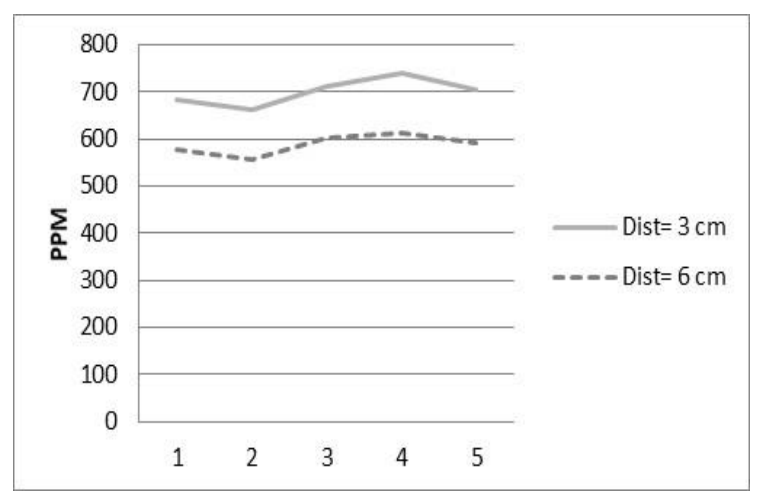

(b)

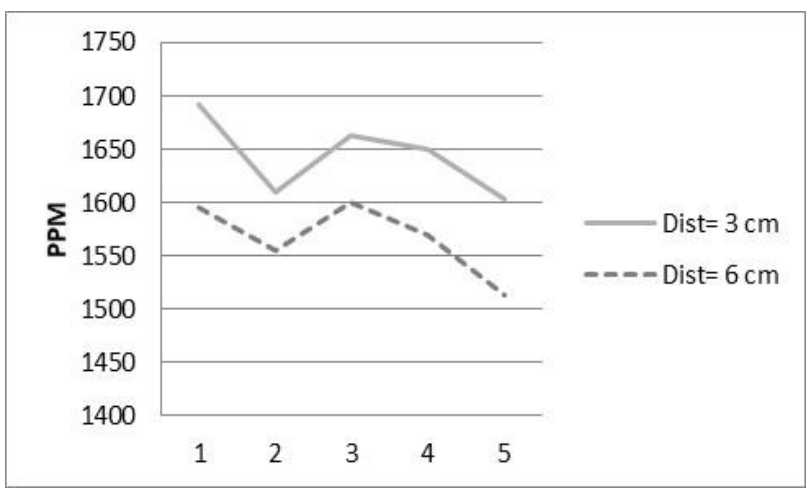

(c)

Figure 4. Response of (a) MQ135 for $\mathrm{CO}_{2}$ with medium size samples, (b) MQ135 for $\mathrm{CO}$ with medium size samples, and (c) MQ6 for $\mathrm{H}_{2}$ with meduim size samples

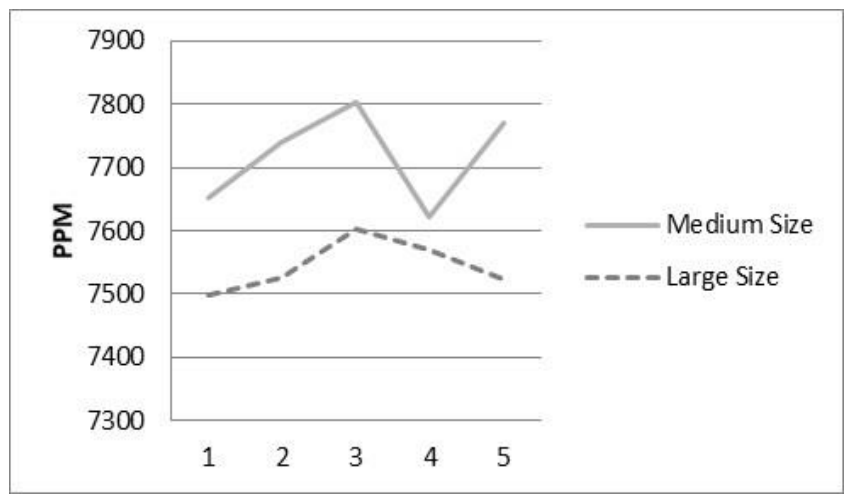

Figure 5. Reponse of MQ135 for $\mathrm{CO}_{2}$ at $3 \mathrm{~cm}$ distance, $31{ }^{\circ} \mathrm{C}$ temperature condition 


\section{CONCLUSION}

The primary goal of this research project is to create a low-cost smart onion sorting machine that includes an automated gas delivery and data acquisition system for detecting volatile compounds released by onions. In the image processing section, the background removal approach was tested and determined to be suitable. It has been observed that the efficiency of the system for deceased onion detection over existing approaches is better. The sensors used are quite affordable, and produce good results in required temperature range; thus they might be used in a storage rooms in several units. To opt for a sturdy sorting machine, the spacings of gas sensor arrays, onion grade, and conveyor belt speed synchronisation must be explored further. It could be adapted to assess post-harvest quality in a variety of other crops.

\section{ACKNOWLEDGEMENTS}

Authors would like to thank Ms Prachi Khivansara, Ms Shradha Bhagure and Mr. Mrunal Wagh for their tireless contribution during testing of prototype. This entire journey was not possible without the help of Management, staff of Electronics and Telecommunication Department of SNJB's K. B. J. College of Engineeing Chandwad for their consistent support.

\section{REFERENCES}

[1] U. K. Paul, G. Das, A. Debnath, and T. Mathur, "Market Integration and Price leadership in India's Onion Market, Review of Market Integration,” SAGE Publications, vol. 8, no. 1-2, pp. 49-64, 1994, doi: 10.1177\%2F0974929216687881.

[2] T. Konduru, G. C. Rains, and C. Li, "A Customized Metal Oxide Semiconductor-Based Gas Sensor Array for Onion Quality Evaluation: System Development and Characterization,” Sensors, vol. 15, no. 1, pp. 1252-1273, 2015, doi: 10.3390/s150101252.

[3] C. Gunathilake, W. M. C. B. Wasala, and K. B. Palipane, "Design, development and evaluation of a size grading machine for onion," Procedia Food Science, vol. 6, pp. 103-107, 2016, doi: 10.1016/j.profoo.2016.02.022.

[4] K. Amit, K. Ramesh, C. Rakesh, K. Davendra, and K. Ashish, “A Survey of Post-Harvest Losses of Onion (Allium CepaL. CV.Agrifound Dark Red) Crop in District Ambala," Progressive Agriculture, vol. 17, no. 2, pp. 272-275, 2017, doi: 10.5958/0976-4615.2017.00048.5.

[5] K. Shukla, G. K. Pandey, M. V. Kumari, A. Vanam, and N. Singh, "A Study on Marketing Pattern of Onion in Nashik District of Maharashtra, India," International Journal of Current Microbiology and Appied Sciences, vol. 8, no. 04, pp. 151-160, 2019, doi: 10.20546/ijcmas.2019.804.016.

[6] S. Sharma, "Economic Analysis of Post Harvest losses in Onion in Jaipur District of Rajasthan," The Asian Journal of Horticulture, vol. 11, no. 1, pp. 124-128, June 2016, doi: 10.15740/HAS/TAJH/11.1/124-128.

[7] B. Verma, "Image Processing Techniques for Grading \& Classification of rice," ICCCT10, International Conference on Computer \& Communication Technology, 2010, pp. 220-223, doi: 10.1109/ICCCT.2010.5640428.

[8] P. Setiya and E. R. Mthuselvam, "A Report on the Study of Onion Value Chain," College of Agricultural Banking, Reserve Bank of Indian, Pune, 2018.

[9] United States Department of Agriculture, "Unites States Standard for Grades of Onions for Processing,” Reprinted Jan 1997. [online] Availabel: https://ag.purdue.edu/hla/fruitveg/Documents/pdf/veg\%20standards/vponion.pdf [accessed on $10 \mathrm{March} 2021]$

[10] K. C. Umani and I. E. Markson, "Development and performance of a mannually operated onions grading machine," Journal of Agriculture and Food Research, vol. 2, pp. 100070, Dec. 2020, doi: 10.1016/j.jafr.2020.100070.

[11] D. Londhe, S. Nalawade, G. Pawar, V. Atkari, and S. Wandkar, "Grader: A Review of different methodsof Grading for Fruits and Vegetables," Agricultural Engineering International, CIGR, vol. 15, no. 3, pp. 217-230, 2013.

[12] A. Mishra, S. K. Jha, and S. Shrestha, "Perfrormance Evaluation of Onion Grader," International Journal of Scientific and Research publication, vol. 10, no. 1, Jan. 2020, doi: 10.29322/IJSRP.10.01.2020.p9768.

[13] G. Gayathri et al., "Design, Development and Evaluation of Manually Operated Onion Grader for Rose Onion," International Journal of Agricultural Engineering, vol. 9, no. 2, pp. 121-129, Oct. 2016, doi: 10.15740/HAS/IJAE/9.2/121-129.

[14] S. Kumar and A. Sharma, "Agricultural Value Chains in India: Prospects and Challenges," Discussion paper produced by CUTS International, April 2016.

[15] G. Singh, Y. Daultani, and R. Sahu, "Investigating the barriers to growth in the Indian food processing sector," Springer link, Aug. 2021. [online] Available: https://link.springer.com/article/10.1007\%2Fs12597-021-00553-1 [accessed on 22 Noveber 2021]

[16] A. Bala, "An Improved Watershed Image Segmentation Technique Using Matlab," International Journal of Science \& Engineering Research, vol. 3, no. 6, pp. 1206-1209, 2012.

[17] C. Wang et al., "A Robust Fruit Image Segmentation algorithm against Varying Illumination for Vision system of Fruit Harvesting Robot," Optik, vol. 131, pp. 626-631, 2017, doi: 10.1016/j.ijleo.2016.11.177.

[18] X. Xiong and B. J. Choi, "Comparative Analysis of Detection Algorithms for Corner and BLOB Features in Image Processing," International Journal of Fuzzy logic and Intelligent Systems, vol. 13, no. 4, pp. 284-290, 2013, doi: 10.5391/IJFIS.2013.13.4.284

[19] T. B. Nguyen and S. T. Chung, “An Improved Real Time BLOB detection for Visual Survelience,” $2^{\text {nd }}$ International Congress on Image And Signal Processing, CISP, Tianjin, China, Oct. 2009, pp 1-5, doi: 10.1109/CISP.2009.5304688.

[20] M. D. Yusuf, Rd. Kusumanto, Y. Oktarina, T. Dewi, and P. Risma, "BLOB Analysis Fruit Recognition and Detection," Computer Engineering and Applications, vol. 7, no. 1, pp. 25-36, Feb. 2018, doi: 10.18495/comengapp.v7i1.237.

[21] Chaithrapallavi and D. S. Mahesh, "A Survey on the developmental Tools Applied in Design of Embedded System," in Special Issue, International Journal of Engineering Research \& Technology (IJERT), 2019.

[22] C. Wang, L. Yi, L. Zhang, D. Xiang, and R. Gao, "Metal oxide gas sensors: Sensitivity and influencing factors," Sensors, vol. 10, no. 3, pp. 2088-2106, 2010, doi: 10.3390/s100302088.

[23] C. Li, N. Schmidt, and R. Gitaitis, "Detection of onion postharvest diseases by analyses of headspace volatiles using a gas sensor array and GC-MS," Food Sci. Technology, vol. 44, no. 4, pp. 1019-1025, 2011, doi: 10.1016/j.1wt.2010.11.036. 
[24] O. E. Gouda, S. H. EI-Hoshy, and S. Salem, "Power Transformer Incipient Faults Diagnosis Based on Dissolved Gas Analysis," TELKOMNIKA (Indonesian Journal of Electrical Engineering), vol. 17, no. 1, pp. 10-16, 2016, doi: 10.11591/ijeecs.v1.i1.pp10-16.

[25] A. D. Wilson, "Diverse applications of electronic-nose technologies in agriculture and forestry," Sensors, vol. 1, no. 13, pp. 2295-2348, 2013, doi: 10.3390/s130202295.

[26] T. Konduru, G. C. Rains, and C. Li, "Detecting sour skin infected onions using a customized gas sensor array," Journal of Food Engineering, vol. 160, pp. 19-27, 2015, doi: 10.1016/j.jfoodeng.2015.03.025.

[27] K. M. M. Adnan, Md. M. Rahman, and S. A. sarker, "Marketing Channels and Post Harvest Practices of Onion of Bogra and Joypurhat District in Bangladesh," Universal Journal of Agriculture Research, HR Publishing, vol. 2, no. 2, pp. 61-66, 2014, doi: 10.13189/ujar.2014.020205.

\section{BIOGRAPHIES OF AUTHORS}

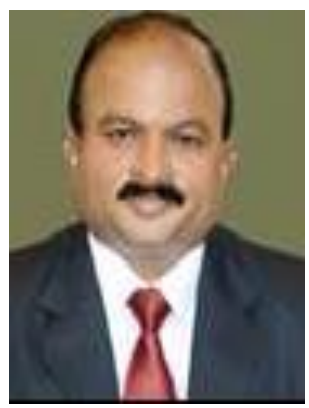

Kokate Mahadeo Digamber (iD 8 SC P Fellow of Institution of Engineers (India) and IETE, N. Delhi. He has graduated from Govt Engineering College, Pune (COEP), MS, India in Electronics \& Telecommunication Engineering discipline and completed his post-graduate and $\mathrm{PhD}$ from Walchand College of Engineering Sangli, and SGGIET, Nanded MS, India respectively. His areas of interest are Signal Processing, Wireless Communication, Mobile Networks, and Data Sciences. He has total thirty years of Teaching and Industry experience. He was a member of the State Advisory Board of Electronics Engineering, MSBTE, Mumbai. Currently he is working as Principal of SNJB's College of Engineering Chandwad, MS, India. Recently he has been awarded as the Best Principal by Computer Scoiety of India, Mumbai. He can be contacted at email: mdkokate66@gmail.com

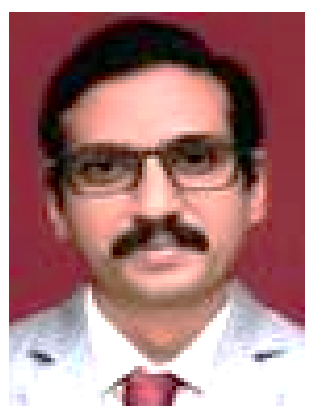

Wankhede Vishal Ashok (D) $8 \mathrm{SC}$ P $\mathrm{He}$ received BE degree from North Maharashtra University, India in 2000, ME degree from Dr Babasaheb Ambedkar Marathwada University in 2007 and $\mathrm{PhD}$ degree from Electronics and Communication Department, Sardar Vallabhbhai National Institute of Technology in 2014. He is currently working as a Principal of S H H J B Polytechnic. His current two major research interests include Wireless Networks especially $3 \mathrm{G}, 4 \mathrm{G}$ and $5 \mathrm{G}$ and interactive computer vision. He was a program chair of the IEEE International conference on Computer and Networking, Malaysia in 2011. He was program director of International Conference on Emerging Trends in Engineering and Technology in 2014 proceeding published by Elsevier. He has been awarded as Engineering Achievement Award by Institution of Engineer, Nashik. He can be contacted at email: principalpoly@snjb.org

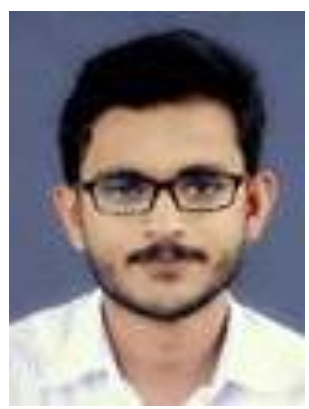

Pawar Dhananjay Jagdish (D) SC P Fellow member of Institution of Engineers (India). He has completed his Masters in engineering in VLSI \& Embedded systems. He is currently working as an Assistant Professor in SNJB's Late Sau. K. B. Jain College of Engineering, Chandwad, affiliated to SPPU, Pune. He has Teaching Experience of 5 years. His areas of interest are IoT, Image Processing, and Embedded Systems. He can be contacted at email: dhananjayjpawar@gmail.com 